\title{
Análise exploratória da utilização do programa de qualidade GESPÚBLICA nas instituições federais de ensino superior
}

\author{
Exploratory analysis on the use of GESPÚBLICA Quality \\ Program in public institutions of Higher Education
}

\author{
Eliane D'Martin Fowler ${ }^{1}$ \\ Carlos Henrique Pereira Mello' \\ Pedro Luiz de Oliveira Costa Neto ${ }^{2}$
}

\begin{abstract}
Resumo: atualmente tem-se dado importância à qualidade dos serviços públicos prestados ao cidadão. Propostas de gestão têm surgido para as organizações privadas, públicas, inclusive para Instituições de Ensino, como um diferencial para a melhoria dos serviços oferecidos. Programas da Qualidade, como o GESPÚBLICA, tornam-se uma opção para Instituições interessadas na melhoria da qualidade. O objetivo desse trabalho é averiguar quais Instituições Federais de Educação Superior possuem um programa da qualidade como o GESPÚBLICA implementado e, a partir de tal informação, conhecer as motivações e as restrições (inibidores), por parte dos gestores, para adesão ao programa. Dentre os fatores motivadores destacam-se melhoria do atendimento e a conquista do cidadão; melhoria contínua na gestão dos processos institucionais; redução da cultura burocrática; gestão baseada em fatos e maior valorização, capacitação dos servidores; gerenciamento eficaz da informação. Dentre os inibidores, citam-se a estrutura/recursos insuficientes para implantação do programa; custos envolvidos no programa; baixa capacitação, quadro reduzido e idade média avançada dos servidores; inexperiência institucional com programas da qualidade; excesso de burocracia e escassez de exemplos consolidados da implementação do programa nas Instituições de Ensino.
\end{abstract}

Palavras-chave: Qualidade na administração pública. Programas da qualidade. Prêmios da qualidade. GESPÚBLICA. Instituições federais de ensino superior.

\begin{abstract}
Currently, great importance has been given to the quality of the public services offered to citizens. Proposals of management have emerged in private and public organizations, including educational institutions, as a differential for the improvement of services offered. Quality programs such as GESPÚBLICA have become an option for institutions interested in improving quality. The aim of this study is to determine which public Institutions of higher education have a quality program such as GESPÚBLICA implemented. The motivations and constraints (inhibitors) to join the program were also investigated. The motivational factors for found for adhesion to the programs are: improvement in the attendance; providing satisfaction; continuous improvement in the institutional management processes; bureaucratic culture reduction; management based on processes and information (facts) and better valuation, qualification of the servers; and efficient information management.. The inhibitor factors found are insufficient structure/resources for the program implementation; program's cost; low qualification and advanced age of the servers; institutional inexperience with Quality Programs; excessive bureaucracy; lack of consolidated examples of the Program implementation in educational institutions.
\end{abstract}

Keywords: Quality of public administration. Quality programs. Quality award. GESPÚBLICA. Public institutions of Higher Education.

\section{Introdução}

A dinâmica global de integração acelerada da economia tem proporcionado uma reflexão profunda sobre os conceitos relativos à soberania e à competitividade das nações, principalmente nos países em desenvolvimento (CORTE, 2006).
Em se tratando de países em desenvolvimento, muitas propostas de gestão têm surgido nas várias áreas empresariais, tanto nas organizações privadas quanto nas públicas. Para obter excelência na qualidade, organizações mundiais têm buscado os programas da

\footnotetext{
${ }^{1}$ Núcleo de Otimização da Manufatura e de Tecnologia da Inovação - NOMATI, Instituto de Engenharia de Produção e Gestão IEPG, Universidade Federal de Itajubá - UNIFEI, CP 50, CEP 37500-903, Itajubá, MG, Brasil,

e-mail: elianefowler@yahoo.com.br; carlos.mello@unifei.edu.br

${ }^{2}$ Universidade Paulista - UNIP, Rua Dr. Bacelar, 1212, Vila Clementino, CEP 04026-002, São Paulo, SP, Brasil,

e-mail: politeleia@uol.com.br
}

Recebido em 26/5/2011 — Aceito em 25/8/2011

Suporte financeiro: CNPq, Fapemig e Capes. 
qualidade a fim de obter avaliação e reconhecimento de sua gestão (MIGUEL, 2001). Isso se aplica também às instituições públicas, especialmente àquelas voltadas para o mercado educacional.

As Instituições de Ensino Superior (IES) se encontram na mesma situação das empresas manufatureiras e de serviços. Evidencia-se que somente com qualidade e operação de maneira competitiva é que as IES estarão hábeis para sobreviver no mercado educacional (KARAPETROVIC; WILLBORN, 1999). Além disso, há uma necessidade de otimização da gestão em torno da qualidade para que as instituições melhorem seu desempenho em benefício do cidadão (BRASIL, 2006a).

Corte (2006) comenta que o desempenho do sistema educacional será fator estratégico para o desenvolvimento do Brasil nos próximos anos. Assim, é importante que, especialmente, as Instituições Federais de Ensino Superior (IFES) identifiquem modelos de avaliação que sejam capazes de extrapolar o conceito clássico de avaliação, que aborda preferencialmente o aspecto didático/pedagógico, relegando outros aspectos para um segundo plano.

Dentre os modelos para gestão e avaliação da qualidade existentes no Brasil, podem-se citar o modelo de garantia da qualidade das normas NBR ISO 9001 (MELLO et al., 2009) e NBR ISO 15419 (ASSOCIAÇÃO..., 2006) e os modelos de sistema de gestão do Prêmio Nacional da Qualidade e do GESPÚBLICA, além dos prêmios setoriais e regionais da qualidade.

O GESPÚBLICA foi instituído em 2005 pelo Decreto $\mathrm{n}^{\circ} 5.378$ (BRASIL, 2005), com a finalidade de contribuir para a melhoria da qualidade dos serviços públicos prestados aos cidadãos e o aumento da competitividade do País. Sua missão é promover a gestão pública orientada para resultados. O programa visa contribuir para a melhoria da qualidade dos serviços públicos prestados ao cidadão e o aumento da competitividade do País (BRASIL, 2006b).

Ao analisar as bases de dados do portal Capes, observa-se que estudos sobre a implantação de programas de melhoria da qualidade em instituições públicas são escassos, tanto nos periódicos nacionais, com indexação no Qualis, quanto nos internacionais. Nos periódicos internacionais, alguns trabalhos identificados tratam da gestão da qualidade total em instituições federais norte-americanas (LIN; OGUNYEMI, 1996) e da avaliação da gestão da qualidade em departamentos de universidades federais (BECKET; BROOKES, 2006; KAUR, MOHAMAD; GEORGE, 2006). Em razão disso, considera-se que o presente trabalho pode contribuir para a base de conhecimento sobre o tema estudado, considerando-se o Brasil como um país em desenvolvimento.

Entretanto, apesar das evidências de que a competência gerencial é um fator crítico para o sucesso organizacional, tem-se observado a não adesão das Instituições Federais a programas da qualidade no Brasil, em especial ao GESPÚBLICA. Assim, o objetivo deste artigo é verificar quais instituições de ensino possuem programas da qualidade implementados, se conhecem o Programa GESPÚBLICA e analisar quais são os fatores motivadores e inibidores para adesão a programas da qualidade como o GESPÚBLICA.

Duas importantes limitações conhecidas do presente estudo são:

- O uso de questionário como um instrumento para coleta de dados embute uma deficiência natural associada ao método de pesquisa. Tal deficiência inclui a fidedignidade das respostas e diferenças entre os respondentes na interpretação e entendimento das questões;

- As respostas representam percepções dos participantes. Isso pode ser influenciado por outras variáveis não consideradas no estudo.

\section{Fundamentação teórica}

\subsection{Qualidade na administração pública e na educação superior}

Milakovich (1998) argumenta que questões como tamanho, complexidade e diversidade do sistema federal deveriam encorajar o governo a buscar iniciativas para a melhoria da qualidade do serviço. Entretanto, falta capacidade para a maioria das instituições governamentais, simultaneamente, reduzir custos, aumentar a produtividade e garantir a motivação dos servidores para estarem orientados às necessidades do cidadão. Concomitantemente, existem problemas relacionados à burocracia; inexperiência; falta de incentivos e benefícios aos servidores; falta de padrões de atendimento ao cliente; resistência e falta de comprometimento, inclusive da alta direção, quanto à implantação de programas da qualidade.

Farazmand (2005) afirma que essa conjuntura requer uma infraestrutura forte, tanto no aspecto institucional quanto cultural, por meio da educação, da capacitação dos servidores (CONOR, 1997; MILAKOVICH, 1998) e da elaboração de programas públicos. Milakovich (1998) complementa ao identificar a necessidade de gerenciamento eficaz da informação, modernização dos equipamentos de trabalho, necessidade de bom atendimento ao usuário e ao mesmo tempo motivar os servidores para fazê-lo.

Segundo Lewis e Smith (1994), os princípios e conceitos da qualidade são compatíveis com as práticas da educação superior. Essas práticas são referentes à: ênfase em serviço; antecipação e atendimento das necessidades dos interessados; melhoria dos processos; melhoria do trabalho em equipe; organização de 
um gerenciamento baseado em liderança; decisões baseadas em fatos e o uso de sistemas de feedback; métodos e ferramentas estatísticas; consideração pelo desenvolvimento dos recursos humanos.

A qualidade na Educação Superior é um conjunto de atributos que existem nas instituições e que, no cumprimento de suas missões, satisfazem as expectativas de seus membros e da sociedade e atingem padrões aceitáveis de desempenho. Esse padrão de qualidade da Instituição de Ensino Superior (IES) está relacionado: ao caráter específico particular vinculado à missão, ao projeto pedagógico, à natureza e ao propósito que a IES define para si (BRASIL, 2006a).

Farazmand (2005) identifica que a chave do sucesso é conquistar a confiança da sociedade nas organizações governamentais e no seu desempenho de qualidade. O governo deve promover e apoiar a qualidade como filosofia para atingir seus objetivos estratégicos.

Quanto à implementação do programa em instituições públicas, Radin e Coffee (1993) afirmam que o tipo de organização, os grupos de interesse, a longevidade e tenacidade da liderança, a motivação para a mudança, o tamanho e a competência dos servidores são fatores a serem considerados. Eles citam alguns quesitos que poderiam motivar a adoção da qualidade no setor público, tais como: auxílio quanto ao manejo adequado dos recursos por parte da instituição; o sucesso que a abordagem obteve na iniciativa privada; alguns casos de sucesso em instituições públicas; projeto com apoio governamental; auxílio à organização quanto à identificação de suas oportunidades de melhoria.

Outros fatores motivadores apontados por Milakovich (1998) são que os programas da qualidade encorajam o comprometimento global da organização, o trabalho em equipe e a melhoria dos resultados da qualidade por intermédio de incentivos.

Entretanto, não há somente fatores que motivam a implementação de programas da qualidade no setor público. Há também alguns traços específicos da organização pública brasileira que impedem a orientação da instituição para o atendimento das necessidades dos cidadãos. Tais fatores são o burocratismo, a interferência política externa à organização, o autoritarismo centralizado, o paternalismo, o apego às regras e rotinas, a supervalorização da hierarquia, a aversão ao empreendedorismo e a descontinuidade da gestão (PIRES; MACEDO, 2006).

\subsection{Modelos de excelência em gestão da qualidade e o GESPÚBLICA}

Martins e Toledo (1998) comentam ser importante que a organização tenha um modelo de referência para elaborar seu programa de gestão para a qualidade. Alguns desses modelos são os das normas de gestão da qualidade ISO 9001 e NBR 15419, e dos Prêmios (nacionais ou setoriais) da Qualidade.

Especificamente para as organizações públicas existem ainda os prêmios de Qualidade do Presidente (EUA), o Ibero-Americano (Fundação IberoAmericana para a Gestão da Qualidade - Fundibeq), o Nacional da Qualidade (Brasil) e o Gespública (Brasil). O Quadro 1 apresenta uma comparação entre esses quatro prêmios.

Analisando-se os prêmios do Quadro 1, percebe-se que o Gespública é o único exclusivamente voltado para organizações do setor público no Brasil. Em virtude disso, ele foi o modelo de gestão escolhido para a realização da presente pesquisa.

O GESPÚBLICA utiliza o Modelo de Excelência em Gestão Pública (MEGP), o qual é uma representação de um sistema gerencial constituído por sete elementos integrados, que orientam a adoção de práticas de excelência em gestão, conforme a Figura 1, que apresenta o relacionamento existente entre os blocos do modelo:

- Primeiro bloco (planejamento): liderança, estratégias e planos e cidadãos e sociedade.

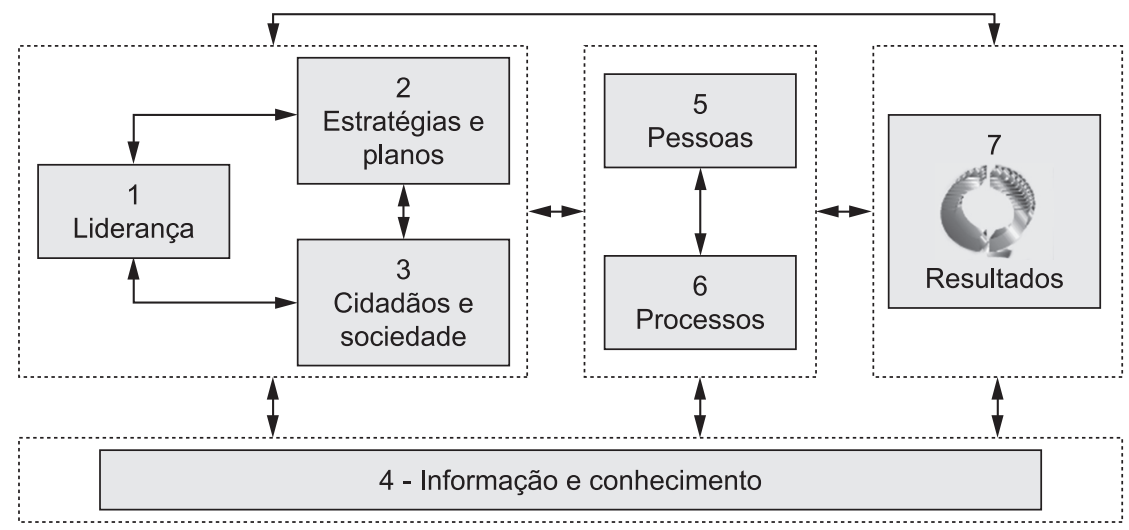

Figura 1. Modelo de excelência e gestão pública. Fonte: Brasil (2006c). 
Quadro 1. Comparação de prêmios da qualidade para o setor público.

\begin{tabular}{|c|c|c|c|c|}
\hline \multirow[t]{2}{*}{ Dados } & \multicolumn{4}{|c|}{ Prêmios } \\
\hline & $\begin{array}{c}\text { Prêmios da } \\
\text { Qualidade do } \\
\text { Presidente }\end{array}$ & $\begin{array}{c}\text { Prêmio } \\
\text { Ibero-Americano da Qualidade }\end{array}$ & $\begin{array}{l}\text { Prêmio Nacional } \\
\text { da Qualidade }\end{array}$ & GESPÚBLICA \\
\hline Ano de fundação & 1988 & 1999 & 1992 & 1998 \\
\hline $\begin{array}{l}\text { Grau de } \\
\text { institucionalização }\end{array}$ & Evento anual & Evento anual & Evento anual & Evento anual \\
\hline Iniciativa & $\begin{array}{l}\text { Governo } \\
\text { Federal Norte- } \\
\text { Americano }\end{array}$ & $\begin{array}{l}\text { Fundación Iberoamericana } \\
\text { para la Gestión de la Calidad - } \\
\text { FUNDIBEQ }\end{array}$ & $\begin{array}{l}\text { Fundação para o } \\
\text { Prêmio Nacional da } \\
\text { Qualidade - Brasil }\end{array}$ & $\begin{array}{l}\text { Governo Federal } \\
\text { do } \\
\text { Brasil }\end{array}$ \\
\hline Organização & $\begin{array}{l}\text { Escritório de } \\
\text { Gestão de } \\
\text { Pessoas dos } \\
\text { EUA }\end{array}$ & FUNDIBEQ & $\begin{array}{l}\text { Fundação para o } \\
\text { Prêmio Nacional da } \\
\text { Qualidade - Brasil }\end{array}$ & $\begin{array}{l}\text { Ministério do } \\
\text { Planejamento, } \\
\text { Orçamento e } \\
\text { Gestão }\end{array}$ \\
\hline $\begin{array}{l}\text { Proposta do } \\
\text { Prêmio }\end{array}$ & $\begin{array}{l}\text { Reconhecer } \\
\text { organizações } \\
\text { que } \\
\text { implementaram } \\
\text { gestão de } \\
\text { qualidade de } \\
\text { modo exemplar }\end{array}$ & $\begin{array}{l}\text { Selecionar os excelentes entre os } \\
\text { melhores no âmbito } \\
\text { das nações da comunidade ibero- } \\
\text { americana }\end{array}$ & $\begin{array}{l}\text { Promover a } \\
\text { conscientização } \\
\text { para a busca da } \\
\text { excelência na gestão } \\
\text { das organizações e } \\
\text { facilitar a } \\
\text { transmissão de } \\
\text { informações e } \\
\text { conceitos relativos } \\
\text { às técnicas e } \\
\text { práticas bem- } \\
\text { sucedidas }\end{array}$ & $\begin{array}{l}\text { Reconhecer } \\
\text { e premiar as } \\
\text { organizações } \\
\text { públicas que } \\
\text { comprovem, } \\
\text { mediante } \\
\text { avaliação feita } \\
\text { por uma banca } \\
\text { examinadora, } \\
\text { desempenho } \\
\text { institucional } \\
\text { compatível com } \\
\text { as faixas de } \\
\text { reconhecimento } \\
\text { e premiação }\end{array}$ \\
\hline $\begin{array}{l}\text { Elegibilidade } \\
\text { básica }\end{array}$ & $\begin{array}{l}\text { Organizações } \\
\text { federais }\end{array}$ & $\begin{array}{l}\text { Organizações que cumpram ao } \\
\text { menos um dos quatro requisitos: } \\
\text { - Tenham ganho o Prêmio Nacional } \\
\text { da Qualidade por organização } \\
\text { associada à FUNDIBEQ; } \\
\text { - Sejam autorizadas pelas } \\
\text { organizações nacionais associadas } \\
\text { à FUNDIBEQ; } \\
\text {-Concorram em categorias não } \\
\text { contempladas no ponto anterior } \\
\text { ou; } \\
\text { - Em seu país não tenham } \\
\text { instituído um Prêmio Nacional da } \\
\text { Qualidade. }\end{array}$ & $\begin{array}{l}\text { Organizações } \\
\text { nacionais ou } \\
\text { estrangeiras, } \\
\text { Sociedades de } \\
\text { Economia Mista, } \\
\text { abertas ou não, } \\
\text { limitadas ou com } \\
\text { outras formas } \\
\text { legais, inclusive as } \\
\text { unidades autônomas } \\
\text { de uma organização } \\
\text { maior }\end{array}$ & $\begin{array}{l}\text { Organizações do } \\
\text { Serviço Público }\end{array}$ \\
\hline
\end{tabular}

Fonte: Adaptado de Ferreira (2003).

Com uma liderança comprometida, atenta às necessidades dos cidadãos, os processos são planejados a fim de atender a essas necessidades;

- Segundo bloco (execução): pessoas e processos;

- Terceiro bloco (controle): resultados. Este bloco tem por objetivo acompanhar a satisfação dos usuários, o orçamento e as finanças, a gestão das pessoas, a gestão de fornecedores e das parcerias institucionais, o desempenho dos serviços/ produtos e dos processos organizacionais;
- Quarto bloco (inteligência da organização): informação e conhecimento. A organização, com base em seus dados internos e externos, busca ações corretivas para melhorar sua gestão e seu desempenho.

\section{Método de pesquisa}

A presente pesquisa é de natureza aplicada, pois visa gerar conhecimentos para aplicação prática do Programa GESPÚBLICA dirigidos à solução de problemas específicos, tal como sua aplicação 
por Instituições Federais de Educação Superior. Quanto aos objetivos, a pesquisa é exploratória, pois investiga as Instituições Federais de Educação Superior no sentido de conhecer quais delas possuem um programa de gestão da qualidade implementado, quais as motivações que teriam para implementar tal programa e quais as dificuldades que poderiam enfrentar durante a implementação desse programa.

Buscou-se inicialmente comparar a gestão das Instituições que haviam implementado um Programa da Qualidade com as que não haviam implementado. Entretanto, verificou-se por meio da consulta ao banco de dados das instituições inscritas nos prêmios, que não havia Instituições Federais inscritas no GESPÚBLICA, nem no Prêmio Nacional da Qualidade.

$\mathrm{O}$ método de pesquisa quantitativa descritiva se mostrou o mais adequado para o propósito da pesquisa de encontrar os motivadores e inibidores na adoção de Programas da Qualidade nas IFES, porque permitiu a quantificação e processamento das variáveis estudadas e a elaboração de modelos explicativos segundo os objetivos do trabalho.

\subsection{Vínculo com o nível teórico}

Inicialmente foi realizada uma fundamentação teórica em que foram encontrados autores como Pires e Macedo (2006); Farazmand (2005); Milakovich (1998); Conor (1997); Radin e Coffee (1993), os quais comentaram em seus trabalhos as possíveis motivações e/ou dificuldades encontradas na implementação de Programas da Qualidade. Também foram identificadas questões quanto aos benefícios adquiridos em Instituições que já possuíam algum programa da qualidade implementado, como em Lewis e Smith (1994).

De acordo com Forza (2002), o primeiro problema que o pesquisador enfrenta é a transformação dos conceitos teóricos em elementos observáveis e mensuráveis. Nessa fase, preocupou-se, também, com a definição operacional dos termos motivadores e inibidores para implementação dos Programas da Qualidade para, na sequência, transformá-los em elementos mensuráveis.

Entendeu-se por motivadoras aquelas questões que poderiam propiciar o desejo da liderança das Instituições Federais a implementarem um Programa

Quadro 2. Possíveis fatores motivadores.

\begin{tabular}{|c|c|}
\hline Autor & Fatores Motivadores \\
\hline Mizikaci (2006) & Competitividade institucional. \\
\hline \multirow[t]{2}{*}{ Pires e Macedo (2006) } & Redução da hierarquia institucional. \\
\hline & Continuidade dos projetos. \\
\hline $\begin{array}{l}\text { Pires e Macedo (2006), } \\
\text { Milakovich (1998) }\end{array}$ & Redução da burocracia. \\
\hline Farazmand (2005) & $\begin{array}{l}\text { Conquista da confiança da sociedade nas organizações governamentais e no seu } \\
\text { desempenho de qualidade. }\end{array}$ \\
\hline Milakovich (1998) & Melhoria dos resultados institucionais. \\
\hline $\begin{array}{l}\text { Milakovich (1998), } \\
\text { Radin e Coffee (1993) }\end{array}$ & Redução de custos, melhor competitividade. \\
\hline Milakovich (1998) & Orientação para o cidadão, melhoria no atendimento. \\
\hline $\begin{array}{l}\text { Milakovich (1998), Conor } \\
\text { (1997) }\end{array}$ & $\begin{array}{l}\text { Incentivos aos servidores, motivação dos servidores, reconhecimento das } \\
\text { contribuições individuais e em grupo dos servidores com o programa. }\end{array}$ \\
\hline Milakovich (1998) & $\begin{array}{l}\text { Gerenciamento eficaz da informação. } \\
\text { Modernização dos equipamentos de trabalho. }\end{array}$ \\
\hline \multirow[t]{6}{*}{ Conor (1997) } & Comunicação clara da visão a todos da organização. \\
\hline & Sistema aberto de comunicação com a gerência. \\
\hline & Envolvimento dos servidores nos programas. \\
\hline & Empowerment. \\
\hline & Avaliações e melhorias contínuas. \\
\hline & $\begin{array}{l}\text { Sistema aberto a críticas, sugestões e reações dos servidores com relação à } \\
\text { implantação da qualidade. }\end{array}$ \\
\hline \multirow[t]{3}{*}{ Radin e Coffee (1993) } & $\begin{array}{l}\text { O sucesso que a abordagem obteve na iniciativa privada. } \\
\text { Alguns casos de sucesso em instituições públicas. }\end{array}$ \\
\hline & Projeto com apoio governamental. \\
\hline & Auxilio a organização quanto à identificação de suas oportunidades de melhoria. \\
\hline
\end{tabular}


de Qualidade, como o GESPÚBLICA. Por meio da revisão da literatura, pôde-se identificar os possíveis motivadores da adesão, apresentados no Quadro 2.

Entendeu-se por inibidoras aquelas questões que poderiam reduzir o desejo da liderança das Instituições Federais a implementarem um Programa de Qualidade, como o GESPÚBLICA. Por intermédio da revisão da literatura, puderam ser identificados os possíveis inibidores à adesão, que são apresentados no Quadro 3.

Forza (2002) explica que, após o desenvolvimento da definição operacional, o pesquisador deve testar sua validade ou a extensão na qual as medições capturam as diferentes facetas do construto. Essa fase foi amplamente discutida com especialistas, a fim de subsidiar a elaboração das perguntas de pesquisa que comporiam o instrumento de coleta de dados.

\subsection{Projeto}

Segundo Forza (2002), no planejamento das atividades, decisões tomadas durante a fase anterior afetam as escolhas nos processos posteriores. Assim, decisões sobre a coleta de dados (entrevistas, $e$-mail, telefone) e o tempo disponível devem ser consideradas no que diz respeito à elaboração do questionário e à escolha da amostra a ser utilizada.

$\mathrm{Na}$ presente pesquisa, foram escolhidas como população as Instituições Federais de Ensino Superior para uma investigação quanto à adesão a Programas da Qualidade como o GESPÚBLICA. A ênfase nesse programa é devida ao fato de ser um Programa do Governo específico para Instituições Públicas. Devido às limitações e dificuldades do método de pesquisa exploratória quantitativa, quanto à dificuldade de acesso aos respondentes e à limitação do tempo de pesquisa, optou-se por não abranger na pesquisa as Instituições Estaduais e Municipais.

Quanto à composição da população, por meio de uma pesquisa realizada pelo Instituto Nacional de Estudos e Pesquisas Educacionais Anísio Teixeira (BRASIL, 2006a), constatou-se a existência de 53 Instituições Federais de Ensino Superior no Brasil.

Bryman (1989) salienta que a escolha da amostra a ser analisada deve levar em conta a sua melhor representatividade para que, a partir dos resultados obtidos, se possa inferir corretamente sobre os resultados da população total.

Nessa pesquisa, como a população é pequena (53 instituições), optou-se pelo envio do questionário a todas as Instituições Federais a fim de obter uma taxa de retorno que permitisse uma análise consistente.

Nessa fase foram definidos os instrumentos de coleta de dados. Optou-se pela elaboração de uma entrevista semiestruturada (vide anexo A) para ser aplicada aos especialistas do Programa GESPÚBLICA e um questionário a ser aplicado à alta direção das Instituições Federais.

A entrevista foi elaborada a fim de esclarecer alguns pontos referentes ao GESPÚBLICA quanto à sua aplicação em Instituições Federais. Os entrevistados foram os especialistas do Programa, a saber, o ex-gerente executivo do GESPÚBLICA, a gerente do GESPÚBLICA e o gerente do Prêmio Nacional do GESPÚBLICA.

$\mathrm{Na}$ etapa de elaboração do questionário (vide anexo B), as vantagens e desvantagens identificadas por Bryman (1989); Lakatos e Marconi (1999); Forza (2002) foram consideradas. Para evitar o

Quadro 3. Possíveis fatores inibidores.

\begin{tabular}{|ll|}
\hline \multicolumn{1}{|c|}{ Autor } & \multicolumn{1}{c|}{ Fatores Inibidores } \\
\hline Pires e Macedo (2006) & $\begin{array}{l}\text { Descontinuidade dos projetos pela próxima gestão. } \\
\text { Interferência política externa à organização. }\end{array}$ \\
$\begin{array}{l}\text { Pires e Macedo (2006); } \\
\text { Milakovich (1998) }\end{array}$ & Excesso de burocracia. \\
Farazmand (2005); & Capacitação dos servidores. \\
Conor (1997); Milakovich (1998); & \\
Radin e Coffee (1993) & Falta de capacidade de reduzir custos. \\
Milakovich (1998) & Falta de capacidade para aumentar a motivação dos servidores. \\
& Inexperiência da instituição e dos servidores. \\
& Problemas com o gerenciamento eficaz da informação. \\
& Hierarquia. \\
Radin e Coffee (1993) & O número de servidores. \\
& O sucesso que a abordagem obteve na iniciativa privada. Alguns casos \\
& de sucesso em instituições públicas. \\
& Pressão das partes interessadas. \\
& Perda de tempo ao implementar o programa sem garantia de sucesso. \\
\end{tabular}


problema da ambiguidade, buscou-se editar o instrumento segundo as sugestões dos especialistas.

O questionário foi elaborado com a utilização da escala ordinal, com quatro níveis de importância, a saber, muito forte, forte, fraco e muito fraco, com relação às assertivas pertinentes quanto às motivações e dificuldades na implementação de um Programa de Qualidade pelas Instituições. Foi reservada uma parte do questionário para comentários adicionais.

Os questionários foram enviados para as reitorias das Instituições, acompanhados de uma carta dirigida ao reitor explicando o objetivo da pesquisa, a garantia de anonimato e a solicitação de colaboração.

Segundo Bryman (1989), a administração de questionários envolve a habilidade do pesquisador para obter a cooperação dos possíveis participantes. Obteve-se, então, a colaboração do reitor da Universidade na qual a pesquisa foi idealizada junto ao Presidente da Associação Nacional dos Dirigentes das IFES (ANDIFES), com o pedido de distribuição, via $e$-mail, da carta de apresentação e do questionário de pesquisa aos reitores das Instituições Federais.

Algumas orientações de Forza (2002) também foram consideradas na elaboração do questionário. Em relação à questão da redação, teve-se a preocupação de se utilizar a terminologia comum às Instituições Públicas. Servidores em cargos de chefia foram consultados quanto à clareza do instrumento. Optou-se pela utilização de questões fechadas para facilitar as respostas e a sua codificação.

Foi elaborada uma carta de apresentação para os reitores a fim de explicar o objetivo do questionário, a garantia de anonimato e a solicitação de colaboração.

\subsection{Teste piloto}

Depois de elaborado, o questionário foi aplicado em dez respondentes: professores de metodologia e estatística, especialistas em qualidade e gestores (pró-reitor, diretor de instituto, secretário de planejamento) na IFES em que atuam os autores. Devido à contribuição dos respondentes, o protocolo passou por dez revisões significativas e sofreu modificações de vocabulário, layout, escala, redução e inclusão de questões.

Nesta etapa, também foram processados os dados referentes às respostas coletadas a fim de identificar e sanar as possíveis dificuldades quanto a esse quesito. Para reduzir as chances de erro no processamento de dados, primeiramente os dados foram registrados manualmente em uma tabela, conferidos e, em seguida, repassados para o computador. Após todas essas etapas o questionário foi validado.

\subsection{Coleta de dados}

Após um processo exaustivo de contatos e tentativas junto às IFES, ocorrido entre abril e outubro de 2007, conseguiu-se uma taxa de respostas correspondentes a $58,5 \%$ das entidades pesquisadas.

Também foram entrevistados especialistas do Programa GESPÚBLICA. Foi realizado um contato, via telefone, com a Gerente da Rede Nacional de Gestão Pública para autorização e agendamento da reunião para o dia 8 de outubro de 2007. Foi aplicado o roteiro elaborado para entrevista semiestruturada (anexo A). Assim, concluiu-se a etapa de coleta de dados.

\section{Resultados da pesquisa}

\subsection{Identidade e dados das instituições respondentes}

Das instituições respondentes, $36 \%$ são da região sudeste, $19 \%$ da região sul, $16 \%$ da região norte, $16 \%$ da região nordeste e $13 \%$ da região centro-oeste.

A Tabela 1 mostra a representatividade das Instituições Federais respondentes, conforme classificação realizada por Brasil (2006a).

Portanto, acredita-se ter obtido uma taxa de retorno que permitiu uma análise consistente, pois, na maioria dos quesitos abordados, obteve-se um percentual de mais de $50 \%$ para as instituições respondentes.

Os questionários foram respondidos por reitores $(46 \%)$, vice-reitores (3\%), pró-reitores $(29 \%)$, secretários de planejamento (6\%) e outros cargos $(16 \%)$, em geral com mais de dois anos na função. Foram considerados apenas os questionários completamente respondidos pelos respondentes. Observou-se que $86 \%$ das instituições, não utilizam programas da qualidade e $14 \%$ responderam que utilizam. Entretanto, não há evidências de um compromisso efetivo, formal e nem visibilidade dessas adesões.

Com relação ao conhecimento do programa, pôde-se verificar que $52 \%$ dos respondentes comentaram que conhecem o programa GESPÚBLICA e $48 \%$ disseram não conhecer. Neste ponto, torna-se oportuno o comentário obtido na entrevista com o Gerente do Prêmio Nacional da Gestão Pública - PQGF GESPÚBLICA:

Tabela 1. Perfil das Instituições respondentes.

\begin{tabular}{lccccc}
\hline & Servidores & Docentes & Doutores & Concluintes & Matrículas \\
\hline Respondentes & $49 \%$ & $60 \%$ & $59 \%$ & $63 \%$ & $63 \%$ \\
Não respondentes & $51 \%$ & $40 \%$ & $41 \%$ & $37 \%$ & $37 \%$ \\
\hline
\end{tabular}


[...] no caso do prêmio, enviamos todo o material aos ocupantes dos cargos superiores (divulgação) dos órgãos públicos. A própria cerimônia do prêmio é uma divulgação. Utiliza-se também a imprensa, TV, rádio, panfleto, folder. Cobre-se por vários meios e, mesmo assim, não se tem garantia de que o material chegará às mãos certas [...] (Gerente do Prêmio Nacional da Gestão Pública).

Portanto, observa-se que, apesar dos esforços de divulgação do Programa, especificamente do prêmio, quase a metade das Instituições Federais não conhece o Programa. Recomenda-se, nesse caso, uma pesquisa mais aprofundada sobre a eficácia da divulgação do Programa.

\subsection{Motivos que levariam as IFES a aderirem a programas da qualidade}

A classificação dos motivos que levariam as IFES a aderirem aos programas da qualidade, apresentados no Quadro 4, foi realizada atribuindo-se peso a cada um dos quesitos respondidos segundo o grau de importância, como mostra a Tabela 2 .

Embora os dados sejam ordinais, para efeito de uma quantificação, atribuíram-se os seguintes valores: o grau muito forte recebeu peso 8; forte, peso 6; moderado, peso 4; e fraco, peso 2, multiplicados pelos respectivos números de respondentes em cada questão. Assim, as questões que obtiveram a classificação maior que 199 foram consideradas muito fortes; as que obtiveram classificação maior que 158 foram consideradas forte; as que obtiveram classificação maior que 148 foram consideradas moderadas; e as que obtiveram classificação inferior a 148 foram consideradas fracas. A forma de classificação utilizada encontra-se na Tabela 2.

O Quadro 5 apresenta as questões classificadas com grau forte ou muito forte, consideradas para efeito do presente trabalho como as mais relevantes, se comparadas com as respectivas citações encontradas na literatura.

Com referência aos critérios do MEGP (Figura 1), observa-se quanto a essas questões que:

- Três são do bloco planejamento:

critério cidadão e sociedade: 8 ) atendimento ao público; 9) conquista da confiança desse público; critério estratégias e planos: 7) facilidade na identificação de prioridades e estratégias.

- Cinco são do bloco execução:

- critério processos: 23) melhoria contínua na gestão dos processos; 27) redução da cultura burocrática; 28) alocação mais eficiente dos recursos e redução dos custos; 20) gestão baseada em fatos;

- critério pessoas: 14) maior valorização, capacitação, reconhecimento e satisfação dos servidores.

Pode-se perceber que os cinco quesitos acima se encadeiam em uma sequência lógica de causas e efeitos.

- Três são do bloco inteligência da organização:

- critério informação e conhecimento:

12) gerenciamento eficaz da informação e comunicação aberta com a gerência; 17) fortalecimento da comunicação; 21) agilidade quanto à tomada de decisão.

O mesmo encadeamento causa e efeito se observa aqui.

Diante dessas questões, fica a dúvida. Se há um instrumento legitimado (Modelo de Excelência em Gestão Pública - MEGP) que permite diagnosticar e estabelecer metas para a implementação de melhorias na qualidade da gestão institucional em Instituições Públicas de Ensino Superior, por que não implementá-lo?

\subsection{Motivos que levam as IFES a não aderirem a programas da qualidade}

Os motivos, em ordem de importância, que levariam as Instituições a não implementarem Programas da Qualidade podem ser observados no Quadro 6. A forma de classificação utilizada encontra-se definida na Tabela 3. Vale lembrar que os pesos totais para a classificação não foram os mesmos, pois o número de respostas foi menor. Optou-se pela reclassificação dos graus muito forte, forte, moderado e fraco, como mostra a Tabela 3. Assim, as questões que obtiveram a classificação maior que 138 foram consideradas muito fortes; as que obtiveram classificação maior que 120 foram consideradas fortes; as que obtiveram

Tabela 2. Classificação das Assertivas Motivadoras.

\begin{tabular}{lccc}
\hline \multicolumn{3}{c}{ Motivadores } \\
\hline \multicolumn{1}{c}{ Importância } & Classificação & $\mathbf{N}^{\mathbf{0}}$ de respondentes & Assertivas \\
\hline Muito forte & $>199$ & $>25$ & $8,12,23,28$ \\
Forte & $>158$ & $>24$ & $7,9,14,17,20,21,27$ \\
Moderado & $>148$ & $<23$ & $6,10,11,13,16,19,22,26,32,34,35,37$ \\
Fraco & $<148$ & $<24$ & $15,18,24,25,29,30,31,33,36$ \\
\hline
\end{tabular}


Quadro 4. Motivos que levariam as IFES a aderirem a Programas da Qualidade.

\begin{tabular}{|c|c|c|c|}
\hline Grau & Assertivas & Questão & Critério \\
\hline \multirow[t]{4}{*}{$\begin{array}{l}\text { Muito } \\
\text { Forte }\end{array}$} & $\begin{array}{l}\text { Gerenciamento eficaz da informação (internamente e } \\
\text { externamente) }\end{array}$ & 12 & $\begin{array}{l}\text { Informação e } \\
\text { conhecimento }\end{array}$ \\
\hline & Alocação mais eficiente dos recursos e redução de custos & 28 & Pocessos \\
\hline & Melhoria contínua na gestão dos processos institucionais & 23 & Pocessos \\
\hline & Melhoria no atendimento ao público (cidadão) & 8 & Cidadão e sociedade \\
\hline \multirow[t]{7}{*}{ Forte } & $\begin{array}{l}\text { Facilitação na identificação das prioridades e estratégias } \\
\text { da instituição }\end{array}$ & 7 & $\begin{array}{l}\text { Estratégias e } \\
\text { planos }\end{array}$ \\
\hline & Maior agilidade quanto à tomada de decisão & 21 & Informação e conhecimento \\
\hline & $\begin{array}{l}\text { Maior valorização, capacitação, reconhecimento e } \\
\text { satisfação dos servidores }\end{array}$ & 14 & Pessoas \\
\hline & $\begin{array}{l}\text { Fortalecimento da comunicação e alinhamento dos vários } \\
\text { departamentos à estratégia institucional }\end{array}$ & 17 & $\begin{array}{l}\text { Informação e } \\
\text { conhecimento }\end{array}$ \\
\hline & Conquista da confiança do cidadão e da sociedade & 9 & $\begin{array}{l}\text { Cidadão e } \\
\text { sociedade/resultado }\end{array}$ \\
\hline & Redução da cultura burocrática & 27 & Processo \\
\hline & Gestão baseada em processos e informações (fatos) & 20 & Processo \\
\hline \multirow[t]{12}{*}{ Moderada } & $\begin{array}{l}\text { Reconhecimento, por parte da sociedade, do esforço } \\
\text { institucional pela busca da qualidade }\end{array}$ & 35 & $\begin{array}{l}\text { Cidadãos e } \\
\text { sociedade }\end{array}$ \\
\hline & Melhoria do aprendizado organizacional & 13 & Informação e conhecimento \\
\hline & $\begin{array}{l}\text { Consolidação da consciência dos valores éticos por parte } \\
\text { de todos os servidores }\end{array}$ & 10 & Pessoas \\
\hline & $\begin{array}{l}\text { Maior foco/controle dos resultados institucionais } \\
\text { (desempenho global) }\end{array}$ & 26 & Processo \\
\hline & Atualização quanto às práticas da qualidade no setor público & 6 & Informação e conhecimento \\
\hline & Melhoria no gerenciamento das relações humanas & 19 & Pessoas \\
\hline & $\begin{array}{l}\text { Divulgação e publicidade da instituição com a melhoria } \\
\text { da imagem institucional }\end{array}$ & 34 & Cidadão e sociedade \\
\hline & $\begin{array}{l}\text { Melhor competitividade da instituição no que tange a } \\
\text { captação de recursos externos }\end{array}$ & 32 & Liderança \\
\hline & Aumento de poder de decisão dos servidores & 16 & Pessoas \\
\hline & $\begin{array}{l}\text { Aquisição de mecanismos que viabilizem a integração } \\
\text { dos cidadãos no processo de definição, implementação e } \\
\text { avaliação da ação institucional }\end{array}$ & 11 & $\begin{array}{l}\text { Cidadãos e } \\
\text { sociedade }\end{array}$ \\
\hline & Mais subsídios para conquista de inovações & 22 & Processo \\
\hline & Programa reconhecido e com apoio governamental & 37 & Estratégias e planos \\
\hline \multirow[t]{9}{*}{ Fraca } & $\begin{array}{l}\text { Obtenção de maior colaboração, por parte dos servidores, } \\
\text { com os cidadãos, colegas e instituição }\end{array}$ & 15 & Pessoas \\
\hline & $\begin{array}{l}\text { Obtenção de um modelo para avaliação e benchmarking } \\
\text { da gestão }\end{array}$ & 33 & $\begin{array}{l}\text { Informação e } \\
\text { conhecimento }\end{array}$ \\
\hline & $\begin{array}{l}\text { Obtenção de feedback externo, realizado por } \\
\text { especialistas, quanto à gestão institucional }\end{array}$ & 36 & $\begin{array}{l}\text { Estratégias e } \\
\text { planos }\end{array}$ \\
\hline & $\begin{array}{l}\text { Aquisição de instrumentos para avaliar o nível de } \\
\text { satisfação dos servidores }\end{array}$ & 18 & Pessoas \\
\hline & $\begin{array}{l}\text { Exemplos de sucesso de outras Instituições de Ensino } \\
\text { que já implantaram o Programa }\end{array}$ & 30 & $\begin{array}{l}\text { Estratégias e } \\
\text { planos }\end{array}$ \\
\hline & $\begin{array}{l}\text { Obtenção de instrumentos que facilitam a identificação } \\
\text { de oportunidades de melhoria }\end{array}$ & 31 & Liderança \\
\hline & Modernização dos equipamentos de trabalho & 24 & Processo \\
\hline & Melhoria da estrutura hierárquica da instituição & 25 & Processo \\
\hline & Continuidade aos programas de qualidade já implantados & 29 & Estratégias e planos \\
\hline
\end{tabular}


Quadro 5. Comparação da teoria identificada com os resultados.

\begin{tabular}{|c|c|c|c|c|c|c|}
\hline \multirow[t]{2}{*}{ Fatores } & \multirow[t]{2}{*}{ Motivadores } & \multicolumn{5}{|c|}{ Autores } \\
\hline & & $\begin{array}{l}\text { Radin e } \\
\text { Coffee } \\
(1993)\end{array}$ & $\begin{array}{l}\text { Conor } \\
(1997)\end{array}$ & $\begin{array}{l}\text { Milakovich } \\
\text { (1998) }\end{array}$ & $\begin{array}{l}\text { Farazmand } \\
\quad(2005)\end{array}$ & $\begin{array}{l}\text { Pires e } \\
\text { Macedo } \\
(2006)\end{array}$ \\
\hline Redução da burocracia & 27 & & & $\mathrm{X}$ & & $\mathrm{X}$ \\
\hline $\begin{array}{l}\text { Conquista da confiança da sociedade } \\
\text { nas organizações governamentais e no } \\
\text { seu desempenho de qualidade }\end{array}$ & 8,9 & & & & $\mathrm{X}$ & \\
\hline $\begin{array}{l}\text { Redução de custos, melhor } \\
\text { competitividade }\end{array}$ & 28 & $\mathrm{X}$ & & $\mathrm{X}$ & & \\
\hline $\begin{array}{l}\text { Orientação para o cidadão, melhoria } \\
\text { no atendimento }\end{array}$ & 8 & & & $\mathrm{X}$ & & \\
\hline $\begin{array}{l}\text { Incentivos aos servidores, } \\
\text { reconhecimento das contribuições } \\
\text { individuais e em grupo dos servidores } \\
\text { com oprograma. }\end{array}$ & 14 & & $\mathrm{X}$ & $\mathrm{X}$ & & \\
\hline Gerenciamento eficaz da informação & 12 & & & $\mathrm{X}$ & & \\
\hline $\begin{array}{l}\text { Modernização dos equipamentos de } \\
\text { trabalho }\end{array}$ & $7,20,21$ & & & $\mathrm{X}$ & & \\
\hline $\begin{array}{l}\text { Comunicação clara a todos os da } \\
\text { organização }\end{array}$ & 17 & & $\mathrm{X}$ & & & \\
\hline $\begin{array}{l}\text { Sistema aberto de comunicação com } \\
\text { a gerência }\end{array}$ & 12 & & $\mathrm{X}$ & & & \\
\hline Avaliações e melhoria contínua & 23 & & $\mathrm{X}$ & & & \\
\hline
\end{tabular}

Quadro 6. Motivos que levariam as IFES a não aderirem a Programas da Qualidade.

\begin{tabular}{|c|c|c|c|}
\hline Grau & Assertivas & Questão & Critério \\
\hline \multirow[t]{5}{*}{ Muito forte } & Quadro reduzido ou idade média avançada dos servidores & 46 & Pessoas \\
\hline & Baixo nível de comprometimento/colaboração dos servidores & 45 & Pessoas \\
\hline & Estrutura/recursos insuficientes para implantação do programa & 48 & Liderança \\
\hline & Excesso de burocracia & 49 & Processo \\
\hline & Escassez de tempo para apoiar o projeto & 38 & Liderança \\
\hline \multirow[t]{5}{*}{ Forte } & Inexperiência institucional com programas de qualidade & 41 & Pessoas \\
\hline & Pressão dos interessados que não consideram prioridade & 54 & Pessoas \\
\hline & Custos envolvidos no programa & 40 & Processo \\
\hline & Baixa capacitação dos servidores & 47 & Pessoas \\
\hline & $\begin{array}{l}\text { Escassez de exemplos consolidados da implementação do } \\
\text { programa nas IFES }\end{array}$ & 51 & $\begin{array}{l}\text { Informação e } \\
\text { conhecimento }\end{array}$ \\
\hline \multirow[t]{5}{*}{ Moderada } & $\begin{array}{l}\text { Incerteza se o programa contribuirá para a melhoria do } \\
\text { desempenho institucional }\end{array}$ & 39 & Resultado \\
\hline & Receio de não continuidade ao programa pela próxima gestão & 42 & Liderança \\
\hline & Baixo índice de divulgação por parte dos programas de qualidade & 52 & Liderança \\
\hline & $\begin{array}{l}\text { Dificuldade de interpretação do vocabulário e da abrangência dos } \\
\text { programas de qualidade }\end{array}$ & 50 & Pessoas \\
\hline & $\begin{array}{l}\text { Estrutura hierárquica que dificulta a aproximação dos servidores } \\
\text { e gestores }\end{array}$ & 43 & Pessoas \\
\hline \multirow[t]{4}{*}{ Fraca } & Baixo índice de dados históricos na instituição & 44 & $\begin{array}{l}\text { Informação e } \\
\text { conhecimento }\end{array}$ \\
\hline & $\begin{array}{l}\text { O SINAES é um modelo abrangente, o que dispensa a utilização } \\
\text { de programas de qualidade }\end{array}$ & 53 & Outros \\
\hline & Exposição dos pontos fracos da instituição à terceiros & 55 & $\begin{array}{l}\text { Cidadãos e } \\
\text { sociedade }\end{array}$ \\
\hline & $\begin{array}{l}\text { A instituição já possui um sistema de gestão adequado à sua } \\
\text { necessidade }\end{array}$ & 56 & Outros \\
\hline
\end{tabular}


Tabela 3. Classificação das assertivas inibidoras.

\begin{tabular}{lccc}
\hline \multicolumn{3}{c}{ Inibidores } \\
\hline \multicolumn{1}{c}{ Importância } & Classificação & $\mathbf{N}^{\mathbf{0}}$ de respondentes & Assertivas \\
\hline Muito forte & $>138$ & $>20$ & $38,45,46,48,49$ \\
Forte & $>120$ & $>20$ & $40,41,47,51,54$ \\
Moderado & $>90$ & $<19$ & $39,42,43,50,52$ \\
Fraco & $<90$ & $<20$ & $44,53,55,56$ \\
\hline
\end{tabular}

classificação maior que 90 foram consideradas moderadas; e as que obtiveram classificação inferior a 90 foram consideradas fracas.

O Quadro 7 apresenta as questões classificadas com grau forte ou muito forte, consideradas para efeito do presente trabalho como as mais relevantes, se comparadas com as respectivas citações encontradas na literatura.

Com referência aos critérios do MEGP (Figura 1), observa-se quanto a essas questões que:

- Duas são do bloco planejamento:

- critério liderança: 38 ) escassez de tempo para apoiar o projeto; 48) estrutura/recursos insuficientes para implantação do programa.

- Cinco são do bloco execução:

- critério pessoas: 41) inexperiência institucional com programas da qualidade; 45) baixo nível de comprometimento/colaboração dos servidores públicos; 46) quadro reduzido de servidores ou idade média avançada dos servidores; 47) baixa capacitação dos servidores; 54) pressão das partes interessadas que acreditam não ser a prioridade no momento.

- critério processos: 40) custos envolvidos no programa; 49) excesso de burocracia.

- Uma é do bloco inteligência da organização:

- critério informação e conhecimento: 51) escassez de exemplos consolidados da implementação do programa nas Instituições de Ensino.

As questões inibidoras citadas como escassez de tempo, falta de estrutura, de experiência, baixo nível de comprometimento, poucos funcionários e pressão podem significar uma falta de comprometimento generalizada por parte das Instituições de Ensino com a qualidade. Se faltam exemplos consolidados, como obter esses exemplos se as instituições não derem o primeiro passo?

\subsection{Análise comparativa entre os fatores motivadores e inibidores}

A identificação de prioridades é um fator motivador para utilização de programas da qualidade, pois contribui para a elaboração e realização das estratégias.
Um dos pontos importantes é a prestação de melhor atendimento ao público em geral e a conquista da confiança desse público. Entretanto, os recursos disponíveis são considerados insuficientes pela liderança. Um fator inibidor destacado é a falta de tempo pela liderança para apoiar o projeto. Cabe aqui questionar como os gestores estão administrando seus recursos e o seu tempo. Esses recursos estão sendo otimizados? Um instrumento de gestão não poderia auxiliar?

Vale lembrar que a conquista da sociedade depende do bom atendimento da instituição. $\mathrm{O}$ bom atendimento tem sido buscado pela iniciativa privada, mas nem sempre percebido nas instituições públicas. Nas instituições públicas, os cargos são vitalícios e em geral não há o reconhecimento do servidor que desempenha sua função com excelência. Para que se melhore $o$ atendimento, pode-se utilizar instrumentos que facilitem a conscientização, capacitação e reconhecimento do servidor. Instrumentos que auxiliem a conhecer melhor a instituição para identificação dos campos prioritários de atuação e elaboração das estratégias.

Uma questão de destaque é que a maior valorização, capacitação, reconhecimento e satisfação dos servidores seria um motivador para a implementação de programas da qualidade. Os inibidores relacionados foram a baixa capacitação, o baixo nível de comprometimento/colaboração, o quadro reduzido e a idade média avançada dos servidores, aliados à pressão das partes interessadas, que acreditam que a implementação de um sistema de gestão pode não ser a prioridade no momento, além da inexperiência institucional com programas da qualidade. Essa inexperiência foi comentada por um dos respondentes ao falar sobre a ausência de cultura interna na área, e pelos Gerentes do Prêmio e da Rede Nacional do GESPÚBLICA em entrevistas concedidas em outubro de 2007.

[...] O modelo exige uma compreensão e o dirigente tem que ter uma motivação para isso. (Gerente do Prêmio GESPÚBLICA).

[...] Além disso, falta à academia estar disposta a olhar sua gestão e se abrir para entender o quanto o modelo de excelência pode agregar ao sistema de gestão. Internalizar a importância de se apropriar de um instrumento que permita 
Quadro 7. Comparação da teoria identificada com os resultados dos inibidores.

\begin{tabular}{|c|c|c|c|c|c|c|}
\hline \multirow[t]{2}{*}{ Fatores } & \multirow[t]{2}{*}{ Inibidores } & \multicolumn{5}{|c|}{ Autores } \\
\hline & & $\begin{array}{c}\text { Radin e } \\
\text { Coffee } \\
\text { (1993) }\end{array}$ & $\begin{array}{l}\text { Conor } \\
\text { (1997) }\end{array}$ & $\begin{array}{l}\text { Milakovich } \\
\text { (1998) }\end{array}$ & $\begin{array}{l}\text { Farazmand } \\
\qquad(2005)\end{array}$ & $\begin{array}{c}\text { Pires e } \\
\text { Macedo } \\
(2006)\end{array}$ \\
\hline Excesso de burocracia & 49 & & & $\mathrm{X}$ & & $\mathrm{X}$ \\
\hline Capacitação dos servidores & 47 & $\mathrm{X}$ & $\mathrm{X}$ & $\mathrm{X}$ & $\mathrm{X}$ & \\
\hline Falta de capacidade de reduzir custos & 40,48 & & & $\mathrm{X}$ & & \\
\hline Falta de motivação dos servidores & 45 & & & $\mathrm{X}$ & & \\
\hline Inexperiência da instituição, servidores & 45,48 & & & $\mathrm{X}$ & & \\
\hline Número de servidores & 41 & $\mathrm{X}$ & & & & \\
\hline $\begin{array}{l}\text { Sucesso que a abordagem obteve na } \\
\text { iniciativa privada }\end{array}$ & 46 & $\mathrm{X}$ & & & & \\
\hline $\begin{array}{l}\text { Alguns casos de sucesso em instituições } \\
\text { públicas }\end{array}$ & 51 & $\mathrm{X}$ & & & & \\
\hline Pressão das partes interessadas & 54 & $\mathrm{X}$ & & & & \\
\hline
\end{tabular}

traçar diagnóstico, estabelecer melhorias e poder se colocar num patamar de excelência de organização no contexto da gestão. (Gerente da Rede Nacional do GESPÚBLICA).

Apesar das dificuldades apontadas, há indícios de que os programas da qualidade contribuem nas questões relacionadas à capacitação e à sensibilização para um maior comprometimento com o trabalho. $\mathrm{O}$ servidor, sentindo-se valorizado, poderá melhorar o seu desempenho profissional. A questão do quadro reduzido de servidores é uma tendência não só na instituição pública, mas também na privada, e não pode ser empecilho para as melhorias. A instituição que é capaz de suprir seus funcionários com novas competências poderá vencer o desafio de ter um quadro enxuto e trabalhar com maior eficácia.

A pressão das partes interessadas é outro desafio que poderá ser vencido com palestras de sensibilização dos programas da qualidade. Nas palavras do ex-gerente executivo do GESPÚBLICA, em entrevista concedida em outubro de 2007:

O processo de adesão baseou-se em reuniões de trabalho e palestras com praticamente todos os dirigentes da Universidade... a reitora conduziu pessoalmente o processo de sensibilização de seus gestores e os resultados neste primeiro ciclo foram relevantes (ex-gerente executivo do GESPÚBLICA).

[..].o processo envolveu a decisão da reitoria. A reitoria convocou a todos para participar, dar o seu posicionamento (Gerente da Rede Nacional do GESPÚBLICA).

Em relação à inexperiência institucional, se as instituições não ousarem implementar, como terão a experiência com os Programas da Qualidade?
Um fato que merece destaque é o fator motivador redução da cultura burocrática, que poderia incentivar as instituições a implementarem os programas da qualidade. Todavia, o excesso de burocracia também foi apontado como inibidor no critério processos. A burocracia é um entrave para que a instituição cumpra com excelência sua missão. Em muitos dirigentes, porém, falta energia para a libertação da administração burocrática. O nível de barreiras na gestão pública, instigado por um modelo de administração burocrática, nos leva a refletir a respeito da efetividade do modelo atual de gestão e como este pode influenciar o trabalho de toda a instituição.

Melhoria contínua na gestão dos processos institucionais, com a gestão baseada em processos e informações (fatos), e a alocação mais eficiente dos recursos e redução de custos foram considerados fatores motivadores. Entende-se que a melhoria dos processos e a gestão baseada em fatos contribuem também no critério pessoas, pois os servidores podem sentir que pertencem a uma estrutura justa e que promove o bem estar e satisfação.

A questão dos custos é contemplada pelos programas, pois promovem a utilização de indicadores de desempenho com ênfase na redução de custos e aumento da qualidade dos serviços prestados. Todavia, a questão dos custos envolvidos com a implementação também é considerada como um fator inibidor. Esse fato sugere uma desconfiança por parte dos gestores de que talvez o custo benefício não seja atraente. Entrevistas com pró-reitores sugeriram que, em algumas instituições, houve a tentativa de implementação com gastos de recursos e tempo que não tiveram continuidade e, portanto, geraram desperdícios para suas instituições. Participantes da pesquisa também comentaram a preocupação em relação aos recursos necessários para a implementação do programa. 
As assertivas motivadoras voltadas para o gerenciamento eficaz da informação, com o fortalecimento da comunicação e alinhamento dos vários departamentos à estratégia institucional e a consequente maior agilidade quanto à tomada de decisão, são requisitos fundamentais para o bom andamento da instituição. $\mathrm{O}$ armazenamento inadequado dos dados, a desorganização e as perdas das informações são problemas que geram retrabalho, perda de tempo e frustração para usuários e servidores.

O problema da perda de dados foi comentado por um dos respondentes ao afirmar que, por falta de padronização em sua universidade, muitos conhecimentos e tarefas se perdem. Outro respondente abordou o tema ao dizer que as iniciativas e avaliações realizadas até o momento não tiveram continuidade e os dados se perderam em sua instituição.

Dois outros respondentes comentaram ainda as dificuldades abordadas em relação ao alinhamento dos vários departamentos à estratégia institucional. Um deles comentou que a estrutura funcional da Universidade é fragmentada, com muita independência entre os diversos setores e as questões políticas balizam decisões que se chocam com os princípios da qualidade. Projetos de grupos se sobrepõem aos interesses do coletivo institucional e parte da comunidade universitária não acredita na viabilidade da gestão da qualidade total. Em sua Universidade, por exemplo, faltou constância de propósitos para garantir a sequência do programa da qualidade. Em outra Universidade, houve resistências partindo dos servidores em relação aos processos de avaliação e medição de desempenho. A descrença e a desmotivação dos funcionários públicos em relação aos resultados obtidos foram citadas por outro respondente.

A escassez de exemplos consolidados da implementação do programa nas instituições de ensino foi também mencionada como um fator inibidor pelos entrevistados. Um dos comentários se relaciona à falta de modelos que tenham sido implementados com sucesso para servir como base para a instituição.

Uma questão comentada pelo ex-gerente executivo do GESPÚBLICA é a posição do MEC ao não adotar um MEGP de classe mundial. Sabe-se que as atividades de avaliação nas Instituições são direcionadas por esse órgão, o qual não aborda o modelo especificado. Assim, as Instituições talvez não sejam incentivadas a conhecer, explorar ou aplicar o modelo.

Outros fatores inibidores que merecem destaque foram abordados pelo ex-gerente executivo do GESPÚBLICA:

O principal fator inibidor para não adesão pelas universidades é a presunção do conhecimento. $\mathrm{O}$ fato de ser a universidade um repositório de doutores presumem seus dirigentes que seu notório saber lhes basta.
[...] há um receio de que a avaliação da gestão avalie também as áreas finalísticas da instituição e seus resultados, e isso a academia não aceita[...]

A avaliação da gestão, preconizada pelo GESPÚBLICA, avalia forma comparativa à eficiência, à eficácia e à efetividade dessas ações/ processos e de seus resultados para a instituição e para a sociedade. No momento em que essa característica é entendida pelos docentes a resistência diminui, pelo menos a ponto de não impedir o engajamento dos principais dirigentes das universidades.

O modelo da universidade é participativo, embora não tenha participação. Aceitar o desafio de que a mudança nem sempre rompe modelos, mas pode fazer modelos operarem com qualidade, ajuda a reduzir a insegurança que muitas vezes impede a adesão ao GESPÚBLICA [...](ex-gerente executivo GESPÚBLICA).

Após esses comentários, resta a consideração de que os instrumentos de gestão da qualidade podem colaborar com as Universidades em suas dificuldades. É importante, entretanto, que a alta direção tenha disposição para conhecer, avaliar e decidir pela sua aplicação.

\section{Conclusão}

Este trabalho teve como objetivo analisar o uso de Programas da Qualidade pelas Instituições Federais, em especial, o GESPÚBLICA, bem como identificar os fatores motivadores e inibidores para adesão dessas Instituições ao Programa.

O Programa tem sido utilizado por vários órgãos públicos brasileiros. Entretanto, tem sido negligenciado pelas IFES. Verificou-se que, independente de o gestor conhecer o programa, do tamanho da universidade e do tempo de atuação no cargo, os fatores que motivariam e inibiriam a implementação do programa apontado estão relacionados aos blocos do MEGP.

O Programa GESPÚBLICA é um convite para uma libertação dos rituais burocráticos, a fim de que se criem administrações comprometidas com valores institucionais que visem o favorecimento da sociedade. Uma das vertentes do Programa é a desburocratização, que busca a eliminação do excesso de burocracia, mediante a desregulamentação e a simplificação de procedimentos.

O presente trabalho identificou uma série de fatores motivadores que podem colaborar para a adesão das IFES ao programa GESPÚBLICA, assim como uma série de fatores inibidores. Tais fatores podem ser utilizados como um guia para orientar as administrações dessas instituições na implantação do programa. 
O Programa GESPÚBLICA, bem como qualquer outro Programa da Qualidade, só acontece com o apoio da alta direção, no caso das IFES, a reitoria. $\mathrm{O}$ poder para a mudança não se encontra nos servidores ou nos processos. O poder para a mudança está na capacidade de gestão. Contudo, há que existir um senso de urgência por parte dos gestores e a percepção de que os benefícios ao aderir ao Programa serão maiores do que a energia despendida.

Apesar do desejo de melhoria da qualidade e maior integração com a sociedade por parte dos gestores, existem agravantes que podem fazer sucumbir essa motivação. Alguns desses agravantes são o apego à burocracia, os recursos considerados insuficientes, a falta de comprometimento, o quadro reduzido dos servidores, a pressão das partes interessadas e a inexperiência intitucional com programas da qualidade. Tais entraves são impeditivos para o sucesso de uma mudança gerencial para a qualidade e para a criação de valor positivo junto ao cidadão. Cabe ao gestor ter coragem e energia para romper com essas barreiras e avançar rumo à excelência.

Os autores do presente trabalho têm a expectativa de que ele possa contribuir para um melhor conhecimento da problemática da qualidade nas IFES e contribuir para a sua melhoria, e se colocam à disposição dos interessados para quaisquer considerações a respeito.

\section{Agradecimentos}

Os autores também agradecem ao $\mathrm{CNPq}$ e à Fapemig e, em especial, à Capes, pelo fomento à esta pesquisa na forma de bolsa de mestrado.

\section{Referências}

ASSOCIAÇÃO BRASILEIRA DE NORMAS TÉCNICAS ABNT. ABNT NBR 15419: Sistemas de gestão da qualidade - Diretrizes para aplicação da ABNT NBR ISO 9001:2000 nas organizações educacionais. Rio de Janeiro: ABNT, 2006.

BECKET, N.; BROOKES, M. Evaluating quality management in university departments. Quality Assurance in Education, v. 14, n. 2, p. 123-142, 2006. http://dx.doi.org/10.1108/09684880610662015

BRASIL. Decreto-lei n ${ }^{\circ} 5.378$ de 23 de fevereiro de 2005. Institui o Programa Nacional da Gestão Pública e Desburocratização - GESPÚBLICA. Diário Oficial da República Federativa do Brasil, Brasília, DF, 24 fev. 2005. p. 2.

BRASIL. Ministério da Educação - MEC. Instituto Nacional de Estudos e Pesquisas Educacionais. Sinopses Estatísticas do Ensino Superior. Brasília: MEC, 2006a. Censos do ensino superior.

BRASIL. Ministério da Educação. Instituto Nacional de Estudos e Pesquisas Educacionais Anísio Teixeira. Avaliação externa de instituições de educação superior: diretrizes e instrumento. Brasília: MEC, 2006b.

BRASIL. Ministério do Planejamento, Orçamento e Gestão. Secretaria de Gestão. Programa Nacional de Gestão Pública e Desburocratização - GESPÚBLICA.
Documento de Referência - Cadernos GESPÚBLICA. Brasília: MEC, 2006c.

BRYMAN, A. Research Methods and Organization Studies. London, 1989.

CONOR, P. E. Total Quality management: A selective commentary on its human dimensions. Public Administration Review, 1997.

CORTE, M. B. Avaliação Institucional de Organizações Educacionais: Método de Auto-avaliação para a Gestão de Organizações Públicas do Ensino Fundamental. 2006. Dissertação (Mestrado em Administração)-Universidade Paulista, São Paulo, 2006.

FARAZMAND, A. Role of Government in an Era of Total Quality Management (TQM) and Globalization: Challenges and Opportunities. Public Organization Review: A Global Journal, v. 5, p. 201-217, 2005.

FERREIRA, A. R. Análise comparativa do prêmio qualidade do governo federal com outros prêmios nacionais e internacionais de qualidade. 2003. Dissertação (Mestrado em Gestão Pública)-Fundação Getúlio Vargas, Brasília, 2003.

FORZA, C. Survey research in operations management: A process-based perspective. International Journal of Operations \& Production Management, v.22, n.2, p.152-194, 2002.

KARAPETROVIC, S. WILLBORN, W. Holonic model for a quality system in academia. International Journal of Quality \& Reliability Management, v. 16, n. 5, 1999. http://dx.doi.org/10.1108/02656719910249847

KAUR, K.; MOHAMAD, P.; GEORGE, S. Quality management service at the University of Malaya Library. Library Management, v. 27, n. 4, p. 249-256, 2006. http://dx.doi.org/10.1108/01435120610668188

LAKATOS, E. M.; MARCONI, M. A. Técnicas de Pesquisa. 4. ed., São Paulo: Atlas, 1999.

LEWIS, R. G.; SMITH, H. D. Total Quality in Higher Education. Delray Beach: St Lucie Press, 1994.

LIN, B.; OGUNYEMI, F. Implications of total quality management in federal services: the US experience. International Journal of Public Sector Management, v. 9, n. 4, p. 4-11, 1996. http://dx.doi. org/10.1108/09513559610128654

MARTINS, R. A.; TOLEDO, J. C. Proposta de modelo para elaboração de programas de gestão para a qualidade total. Revista de Administração, v. 33, n. 2, p. 52-59, 1998.

MELLO, C. H. P. et al. ISO 9001:2008: Sistema de Gestão da Qualidade para Operações de Produção e Serviços. São Paulo: Editora Atlas, 2009.

MIGUEL, P. A. C. Comparing the Brazilian national quality award with some of the major prizes. The TQM Magazine, v. 13, n. 4, 2001. http://dx.doi. org/10.1108/09544780110391675

MILAKOVICH, M. E. Public Sector the state of resultsdriver customer service quality in government. National: Spring, 1998.

PIRES, J. C. S.; MACEDO, K. Cultura Organizacional em Organizações Públicas no Brasil. Revista de Administração Pública - RAP,2006.

RADIN, B. A.; COFFEE, J. N. A critique of TQM: problems of implementation in the public sector. Public Administration Quartely, v. 17, n. 1, p. 42-54, 1993. 


\section{Anexo A - Roteiro de entrevista}

1) O programa é adequado às Universidades Federais?

2) O que dificulta as IFES a participarem dos programas?

3) Quais são as universidades Federais que aderiram ao Programa?

4) Qual o avanço obtido pela USP com relação aos procedimentos e aperfeiçoamento da prestação de serviços da Universidade aos cidadãos e à sociedade?

5) Como tem sido a divulgação do Programa junto às Universidades?

6) O que deveria ser efetivado, concretizado para estimular uma maior adesão das IFES ao Programa?

7) Quais esforços têm sido realizados para tornar as Universidades parceiras do programa?

8) O que falta para que as universidades tenham uma maior abertura ao programa GESPÚBLICA ou aos programas da qualidade?

\section{Anexo B - Questionário}

1) Nome da Instituição:

2) Cargo atual do respondente: ( ) reitor ( ) vice-reitor ( ) pró-reitor ( )Secretário de Planejamento

( ) Outros. Qual?

3) Tempo de atuação no cargo atual: ( ) menos de 1 ano ( ) 1-2 anos ( ) 2-3 anos ( ) mais de 3 anos

4) A Instituição utiliza algum Programa de Gestão da Qualidade? ( ) SIM ～( ) NÃO

4.1) Se SIM, qual? ( ) ABNT NBR 9001 （）GESPÚBLICA （）ABNT NBR15419 ( ) Outros

5) A instituição conhece o Programa Nacional da Gestão Publica e Desburocratização - GESPÚBLICA?

\section{( ) SIM ( ) NÃO}

Quais dos itens abaixo levariam a Instituição à implantação de um programa de qualidade? Não é necessário assinalar todos os itens. Por favor, assinale somente os itens pertinentes com o seu respectivo grau de importância conforme informações a seguir:

\begin{tabular}{|c|c|c|c|c|}
\hline \multirow[t]{2}{*}{ Itens } & \multicolumn{4}{|c|}{$\begin{array}{c}\text { Grau } \\
\text { importância }\end{array}$} \\
\hline & ++ & + & - & - - \\
\hline \multicolumn{5}{|l|}{ 6. Atualização quanto às práticas da qualidade no setor público } \\
\hline \multicolumn{5}{|l|}{ 7. Facilitação na identificação das prioridades e estratégias da instituição } \\
\hline \multicolumn{5}{|l|}{ 8. Melhoria no atendimento ao público (cidadão) } \\
\hline \multicolumn{5}{|l|}{ 9. Conquista da confiança do cidadão e da sociedade } \\
\hline \multicolumn{5}{|l|}{ 10. Consolidação da consciência dos valores éticos por parte de todos os servidores } \\
\hline \multicolumn{5}{|l|}{$\begin{array}{l}\text { 11. Aquisição de mecanismos que viabilizem a integração dos cidadãos no processo de } \\
\text { definição, implementação e avaliação da ação institucional }\end{array}$} \\
\hline \multicolumn{5}{|l|}{ 12. Gerenciamento eficaz da informação (internamente e externamente) } \\
\hline \multicolumn{5}{|l|}{ 13. Melhoria do aprendizado organizacional } \\
\hline \multicolumn{5}{|l|}{ 14. Maior valorização, capacitação, reconhecimento, e satisfação dos servidores } \\
\hline \multicolumn{5}{|l|}{$\begin{array}{l}\text { 15. Obtenção de maior colaboração por parte dos servidores com os cidadãos, colegas e } \\
\text { instituição }\end{array}$} \\
\hline \multicolumn{5}{|l|}{ 16. Aumento de poder de decisão dos servidores } \\
\hline \multicolumn{5}{|l|}{$\begin{array}{l}\text { 17. Fortalecimento da comunicação e alinhamento dos vários departamentos à estratégia } \\
\text { institucional }\end{array}$} \\
\hline 18. Aquisição de instrumentos para avaliar o nível de satisfação dos servidores & & & & \\
\hline 19. Melhoria no gerenciamento das Relações Humanas & & & & \\
\hline
\end{tabular}

++: Muito forte; +: Forte; -: Fraco; --: Muito fraco. 


\begin{tabular}{|c|c|c|c|c|}
\hline \multirow[t]{2}{*}{ Itens } & \multicolumn{4}{|c|}{$\begin{array}{c}\text { Grau } \\
\text { importância }\end{array}$} \\
\hline & ++ & + & - & -- \\
\hline 20. Gestão baseada em processos e informações (fatos) & & & & \\
\hline 21. Maior agilidade quanto à tomada de decisão & & & & \\
\hline 22. Mais subsídios para conquista de inovações & & & & \\
\hline 23. Melhoria contínua na gestão dos processos institucionais & & & & \\
\hline 24. Modernização dos equipamentos de trabalho & & & & \\
\hline 25. Melhoria da estrutura hierárquica da instituição & & & & \\
\hline 26. Maior foco/controle dos resultados institucionais (desempenho global) & & & & \\
\hline 27. Redução da cultura burocrática & & & & \\
\hline 28. Alocação mais eficiente dos recursos e redução de custos & & & & \\
\hline 29. Continuidade aos programas de qualidade já implantados (caso já tenha implantado algum) & & & & \\
\hline 30. Exemplos de sucesso de outras Instituições de Ensino que já implantaram o Programa & & & & \\
\hline 31. Obtenção de instrumentos que facilitam a Identificação de oportunidades de melhoria & & & & \\
\hline 32. Melhor competitividade da instituição no que tange à captação de recursos externos & & & & \\
\hline 33. Obtenção de um modelo para avaliação e benchmarking da gestão & & & & \\
\hline 34. Divulgação e publicidade da instituição com melhoria da imagem institucional & & & & \\
\hline 35. Reconhecimento, por parte da sociedade, do esforço institucional pela busca da qualidade & & & & \\
\hline 36. Obtenção de feedback externo, realizado por especialistas, quanto à gestão institucional & & & & \\
\hline 37. Programa reconhecido e com apoio governamental. & & & & \\
\hline
\end{tabular}
++: Muito forte; +: Forte; -: Fraco; --: Muito fraco.

Quais dos itens abaixo dificultariam a implantação de um programa de qualidade na Instituição? Não é necessário assinalar todos os itens. Por favor, assinale somente os itens pertinentes com o seu respectivo grau de importância.

\begin{tabular}{|c|c|c|c|c|}
\hline \multirow[t]{2}{*}{ Itens } & \multicolumn{4}{|c|}{$\begin{array}{c}\text { Grau } \\
\text { importância }\end{array}$} \\
\hline & ++ & + & - & -- \\
\hline 38. Escassez de tempo para apoiar o projeto & & & & \\
\hline 39. Incerteza se o programa contribuirá, de fato, para a melhoria do desempenho institucional & & & & \\
\hline 40. Custos envolvidos no programa & & & & \\
\hline 41. Inexperiência institucional com programas de qualidade & & & & \\
\hline 42. Receio de não continuidade ao programa pela próxima gestão & & & & \\
\hline 43. Estrutura hierárquica que dificulta aproximação dos servidores e gestores & & & & \\
\hline 44. Baixo índice de dados históricos na instituição & & & & \\
\hline 45. Baixo nível de comprometimento/colaboração dos servidores públicos & & & & \\
\hline 46. Quadro reduzido de servidores ou idade média avançada dos servidores & & & & \\
\hline 47. Baixa capacitação dos servidores & & & & \\
\hline 48. Estrutura/recursos insuficientes para implantação do programa & & & & \\
\hline 49. Excesso de burocracia & & & & \\
\hline 50. Dificuldade de interpretação do vocabulário e da abrangência dos programas de qualidade & & & & \\
\hline $\begin{array}{l}\text { 51. Escassez de exemplos consolidados da implementação do programa nas Instituições de } \\
\text { Ensino }\end{array}$ & & & & \\
\hline 52. Baixo índice de divulgação por parte dos programas de qualidade & & & & \\
\hline $\begin{array}{l}\text { 53. O SINAES é um modelo abrangente, o que dispensa a utilização de Programas de } \\
\text { Qualidade }\end{array}$ & & & & \\
\hline 54. Pressão das partes interessadas que acreditam não ser a prioridade no momento & & & & \\
\hline 55. Exposição dos pontos fracos da instituição a terceiros (auditores, consultores) & & & & \\
\hline 56. A instituição já possui um sistema de gestão adequado à sua necessidade. & & & & \\
\hline
\end{tabular}

\section{Comentários complementares}

Por favor, escreva seus comentários adicionais. 